\title{
Effect of Gamma- Irradiation on Structure, Morphology and Thermal Properties of Novel Polyamide Based Thermoset Obtained by Double Cycloaddition
}

\author{
Balakrishna Kalluraya $^{1 *}$, Kaushik B R ${ }^{1}$, H. M. Somashekarappa ${ }^{2}$ \\ ${ }^{1}$ Department of Studies in Chemistry, Mangalore University, Mangalagangothri-574199, Karnataka state, India \\ ${ }^{2}$ Centre for Application of Radioisotopes and Radiation technology, Mangalore University, Mangalagangothri- \\ 574199, Karnataka State, India.
}

* Corresponding author email: bkalluraya @gmail.com

Received: 30 April 2020 / Revised: 16 June 2020 / Accepted: 27 June 2020 / Published: 05 July 2020

\begin{abstract}
Cycloaddition reactions gained prominence in macromolecular chemistry for generating macromolecules because of high yields of these reactions, which is a key tool that drives polyaddition reactions. Cycloaddition reaction plays major role in extension of polymerisation or in other words high conversions of monomers to macromolecules of high molecular weights. Until the late 1990s, the major studies regarding cycloadditions in novel polymer synthesis were related to polyaddition reactions. Since then in the field of polymer synthesis the affirmative strengths of these cycloaddition reactions have been exhibited in multi fold polymer design and headway material architecture. Future demand exists in unlatching the capacity of these novel synthetic routes for advanced applications in catalysis, separation, optoelectronics, and analytical media. Thus, we have developed an able and productive synthetic podium for the preparation of a new class of polyimide based on the double 1, 3dipolar cycloaddition of thiasydnone with bis-maleimide. This paper reports the effect of gamma irradiation on the changes in physico-chemical properties of the polyamide based thermoset synthesised by double cycloaddition approach. The thermoset synthesized by this exclusive approach were irradiated with gamma doses in the range 10-300 kGy. The substantial effect of gamma radiation and the structural modifications induced on the thermoset have been studied as a function of dose using different characterization techniques such as Fourier transform infrared spectroscopy (FTIR), Xray diffraction (XRD), differential scanning calorimetry- thermo gravimetric analysis (DSC-TGA), Field Emission Scanning Electron Microscope (FESEM) and UV-Vis Spectroscopy.
\end{abstract}

Keywords: Thiasydnone, double cycloaddition, gamma irradiation, thermoset.

\section{Introduction}

The chemistry of mesoionic compounds are boomingly detailed in the literature [1]. Sydnones, thiasydnones, munchnones and nitrones mainly comes under this category. Among these mesoionic ring systems, sydnones and their functionalised ancestrals have secured much of magnetism because of their wide variety of synthetic and pharmacological applications [2-4]. They have been investigated comprehensively as possible dipoles and doping polymers [5]. From last few years, there is an immense concentration on polymeric materials, which have multi sided application due to their enormous adaptability, highly tailored production and cost credibility, and it is useful in multiple areas such as engineering technology, defence supplies, and medical devices [6]. Aerospace and microelectronic production corporations essentially demands the advancement of featherweight macro molecules with admirable and exceptional chemical, thermal, and mechanical toughness and durability [7] to ensure proper use of polymers or macro molecules in applications involving exposure to ionizing radiation. 
Effect of Gamma- Irradiation on Structure, Morphology and Thermal Properties of Novel Polyamide Based Thermoset..........

The irradiation of polymeric materials using ionizing radiation is one of the encouraging approaches because of its high penetration proficiency, for modifying or deforming the polymeric materials, like chemical, structural, optical, surface and mechanical properties [8-10]. The synergic effect of radiation with polymeric materials stimulates alterations in the material structure, which causes formation or disappearance of chemical bonds, the production of free radicals, chain scission, cross-linking, chain aggregation and release of hydrogen gas [11-13]. Sometimes in the presence of oxygen, oxidation process starts and oxygen interacts with the free radicals and generates oxidised products [14]. Usually, oxidation and degradation increases with increasing irradiation dose. Different polymers have different reverberations to radiation, which are fundamentally related to the chemical structures of the polymers. As a reflection of this, physico-chemical characteristics of the polymer gets modified [1520]. By these observations, the development of polymeric material that can with stand high dose of gamma irradiation without change in their intrinsic properties still remains as a major challenge.

The versatile structural characteristics and properties of mesoionic compounds have gained the attention of many researchers to the field of photonics and non-linear optical studies [21-24] and medicinal chemistry [25-31]. Admitting the fact that meso-ionic compounds are well explored in the field of non-linear optical studies and medicinal chemistry, these are less explored in the field of polymer synthesis. The 1,3-dipolar cycloaddition reaction of sydnone to olefinic double bond is well established to produce firstly an unstable 1:1 primary additional product, which in later stage of the reaction eliminates carbon dioxide and undergoes a 1,3-proton shift to become a pyrazoline or eliminates neutral molecule to form a pyrazole system as a final solid product. This bis additional product is due to double cycloaddition of sydnone to two molecules of the olefin after elimination of carbon dioxide. Even though this kind of double cycloaddition reaction is reported with certain olefins and bis maleimides with sydnones and only a finite number of non aromatic thermosets being prepared using azide-alkyne click chemistry [32-33], no reports were available till date on the synthesis of polymer by double cycloaddition reaction of thiasydnone with bismaleimides. By these observations and in continuation of our work [34-35] we report herein our attempts for the development of a polymeric system that can with stand a high gamma irradiation by the double cycloaddition of thiasydnone with bis-maleimide.

So, in the present work we subjected thiasydnone, a mesoionic compound with 1,11-(methhylenedi4,1-phenylene) bismaleimide for double cycloaddition and synthesized a novel macro molecule. The novel polymer thus synthesized was characterised by spectral and microscopic techniques. The novel polymer was irradiated with gamma rays at a dose range of 10-300kGys. The stability of polymer on exposure to ionizing radiation has been studied extensively and several attempts to correlate relative stability with chemical structure of polymers upon irradiation have been made and ensured that this polymer could fit were applications involving exposure to ionizing radiation takes the first priority.

\section{Materials and Methods}

Bis- maleimides were procured from SigmaAldrich and used as such without further purification. The infrared spectra of the pristine and irradiated polymer samples were recorded on a Bruker Alpha, Fourier-transform infrared (FTIR) spectrophotometer (Germany). Thermogravimetric analysis of the pristine and irradiated polymers was carried out using Shimadzu DTG60(Japan) thermo gravimetric analyzer. Differential Scanning Calorimetry was performed in the temperature range from room temperature up to $700{ }^{\circ} \mathrm{C}$ at a heating rate $10{ }^{\circ} \mathrm{C} / \mathrm{min}$, for both pristine and irradiated representatives. The nature and morphology of the pristine and irradiated polymers were studied by the Field Emission Scanning Electron Microscope (FESEM) connected with Energy Dispersive Spectroscopy technique (FESEM Ultra 55 KarlZeiss). 
$\mathrm{UV} / \mathrm{Vis}$ spectroscopy measurements were conducted by UV/Vis Spectrophotometer (Model Tomos UV-1800) in the wavelength range from 800 to $190 \mathrm{~nm}$, in reflection mode. The irradiation was carried out with ${ }^{60} \mathrm{Co}$ Gamma source of capacity 13455Ci (497.8TBq), at a dose rate of $4 \mathrm{kGy} / \mathrm{hr}$ at CARRT, (Centre for Application of Radioisotopes and Radiation technology), Mangalore University, Mangalagangothri, India. The samples were irradiated at different absorbed doses 10, 50, 100, 200 and $300 \mathrm{kGy}$, under similar condition.

\subsection{Procedure for the preparation of polymer}

Potassium hydroxide $(1.035 \mathrm{~g}, 0.0184 \mathrm{~mol})$ was taken in a round bottom flask in $10 \mathrm{~mL}$ of alcohol and phenyl hydrazine (1) $(1.0 \mathrm{~g}, 0.00924 \mathrm{~mol})$ was added portion wise and the contents were stirred for 30 minutes. Then the reaction mixture was cooled to $0{ }^{\circ} \mathrm{C}$ and added $\mathrm{CS}_{2}(0.35 \mathrm{~mL}$, $0.00462 \mathrm{~mol}$ ) drop wise until yellow coloured solid of potassium $\beta$ - phenyl dithiacarbazate was formed. The potassium $\beta$ - phenyl dithiacarbazate was filtered and washed with several batches of diethyl ether until a pure white coloured amorphous powder of potassium $\beta$ - phenyl dithiacarbazate was obtained. This Potassium $\beta$ phenyl dithiacarbazate (2) $(1.87 \mathrm{~g}, 0.00925 \mathrm{~mol})$ was dissolved in $25 \mathrm{~mL}$ of water and the contents were stirred at $0{ }^{\circ} \mathrm{C}$. To this solution, benzoyl chloride $(1.55 \mathrm{~mL}, 0.011 \mathrm{~mol})$ was added drop wise. Care was taken to maintain the temperature in this range. After 3 hours, the yellow precipitate of thia sydnone (3) formed was collected by filtration and recrystallized from ethanol to get the pure thia sydnone (3) (Scheme-1). This thiasydnone $(2.50 \mathrm{~g}, 0.00922 \mathrm{~mol})$ and $1,1^{1}$ (methhylenedi-4,1-phenylene) bismaleimide ( $3.305 \mathrm{~g}, 0.00922 \mathrm{~mol}$ ) were taken in $20 \mathrm{~mL}$ of $\mathrm{N}, \mathrm{N}$ dimethylformamide in a $\mathrm{RB}$ flask and were stirred under nitrogen atmosphere at $160^{\circ} \mathrm{C}$. Carbon disulphide started to evolve at $60^{\circ} \mathrm{C}$ and was vented through a micro bubbler. Progress of the reaction was monitored by TLC. Once the reaction was complete, the hot solution was poured with care into crushed ice. The polyimide solidified was washed using water and then with

acetone and dried. A brown coloured polyimide was obtained in good yield.

\subsection{Reaction scheme}

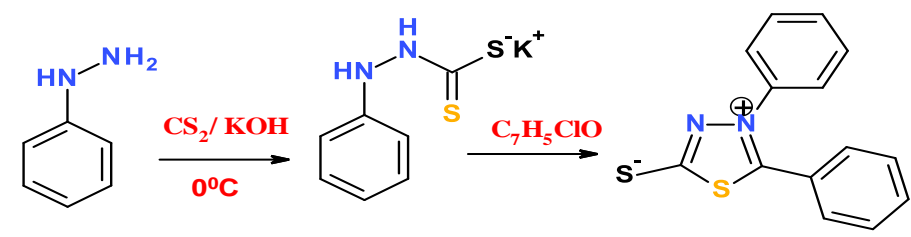

(1)

(2)

(3)

Scheme-1. Preparation of thiasydnone<smiles>Sc1nnc(-c2ccccc2)s1</smiles>

(3)

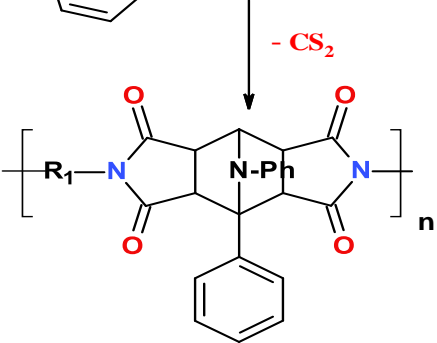

(5)

Scheme-2. Double cycloaddition

\section{Result and Discussions}

For synthesizing polymer, the synthetic methodology we used was double cycloaddition reaction technique between thiasydnone and bismaleimide. Several reactions, such as $\mathrm{Cu}(\mathrm{I})$ catalyzed azidealkyne reaction, tetrazinenorbornene reaction, Diels-Alder cycloaddition reaction showcases similar features and have been finding applications in fabrication. Among them, the $\mathrm{Cu}(\mathrm{I})$-catalyzed alkyne-azide 1,3dipolar cycloaddition (CuACC) is one of the preferred techniques. CuACC has been successfully found application in many fields of materials chemistry [36-37]. But the major problem is the toxicity of leftover Copper and selectivity in some cases. This brings a potential limitation of the CuACC reaction when it is used to synthesize or functionalize materials for different applications especially biomedical applications [38-39]. Cycloaddition reactions are a class of reactions that possess the versatile features like high selectivity, excellent yield, rapid 
Effect of Gamma- Irradiation on Structure, Morphology and Thermal Properties of Novel Polyamide Based Thermoset..........

reaction and zero side reactions [40-42]. But the major challenge in macromolecular synthesis is to use equimolar amounts of the building blocks. In addition to this, a simple large-scale purification process and a reasonable timescale and require no tedious fine-tuning of reaction conditions. So here we used most appreciated double cycloaddition reaction for the synthesis.

\subsection{FT-IR Analysis}

The structure of the newly synthesized polymer was characterized by recording the IR spectra. For polymer sample 5, a strong absorption band observed in the region of $\sim 1649 \mathrm{~cm}^{-1}$ and $\sim 1707$ $\mathrm{cm}^{-1}$ corresponds to the stretching vibrations of two amide carbonyl groups. The $-\mathrm{C}=\mathrm{C}$ stretching bands were observed at $\sim 1514 \mathrm{~cm}^{-1}$. The $-\mathrm{C}-\mathrm{H}$ bending band was observed at $1386 \mathrm{~cm}^{-1}$. The $-\mathrm{C}-\mathrm{N}$ bending band was observed at $1171 \mathrm{~cm}^{-1}$. The absorption band values corresponding to each infrared vibrations of polymers irradiated with different doses are given in Table-1.

Table 1: IR absorption bands corresponding to the functional groups of the polymer 5.

\begin{tabular}{|c|c|c|c|c|c|}
\hline \multicolumn{5}{|c|}{ Absorption band $\left(\mathrm{cm}^{-1}\right)$} & \multirow{2}{*}{$\begin{array}{l}\text { Functional } \\
\text { group }\end{array}$} \\
\hline \multicolumn{5}{|c|}{ Polymer sample 5} & \\
\hline $10 \mathrm{kGy}$ & $50 \mathbf{k G y}$ & $100 \mathrm{kGy}$ & 200kGy & $300 \mathrm{kGy}$ & \\
\hline 1708,1647 & 1707,1647 & 1706,1646 & 1708,1647 & 1707,1647 & $\begin{array}{l}\mathrm{C}=\mathrm{O} \\
\text { stretch. }\end{array}$ \\
\hline 1513 & 1513 & 1514 & 1514 & 1514 & $\begin{array}{l}\mathrm{C}=\mathrm{C} \\
\text { stretch. }\end{array}$ \\
\hline 1387 & 1388 & 1388 & 1387 & 1386 & C-H bend. \\
\hline 1172 & 1175 & 1173 & 1172 & 1175 & C-N bend. \\
\hline
\end{tabular}

The gamma irradiated samples of the polymers showed IR vibrational absorption bands approximately at the same wave numbers as that of pristine sample. The polymer showed no distinguishable changes in structure between non-irradiated representative and those irradiated with particular doses of gamma rays. The stretching vibrations of two amide carbonyl groups for the irradiated polymer samples $(10 \mathrm{kGy}-300 \mathrm{kGy})$ were observed in the region of
$1708 \mathrm{~cm}^{-1}-1706 \mathrm{~cm}^{-1}$ and $1647 \mathrm{~cm}^{-1}-1646$. The $\mathrm{C}=\mathrm{C}$ - stretching bands for irradiated polymer was observed in the region of $1514 \mathrm{~cm}^{-1}-1513 \mathrm{~cm}^{-}$ 1. Similarly $-\mathrm{C}-\mathrm{H}$ bending for the irradiated sample was observed in the region of $1388 \mathrm{~cm}^{-1}$ $1386 \mathrm{~cm}^{-1}$. Even the $-\mathrm{C}-\mathrm{N}$ bending band was observed at the same wave number as that of the pristine. The IR spectra of the polymer irradiated with different doses of gamma radiation are as shown in Fig. 1 and Fig. 2.

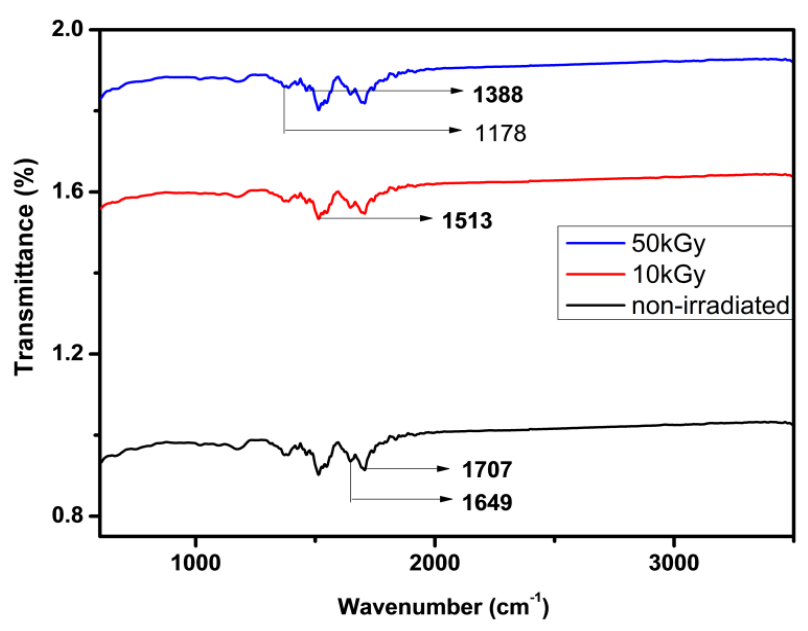

Figure 1: FT-IR spectra of pristine and polymer (5) irradiated with dose of $10 k G y$ and $50 k G y$

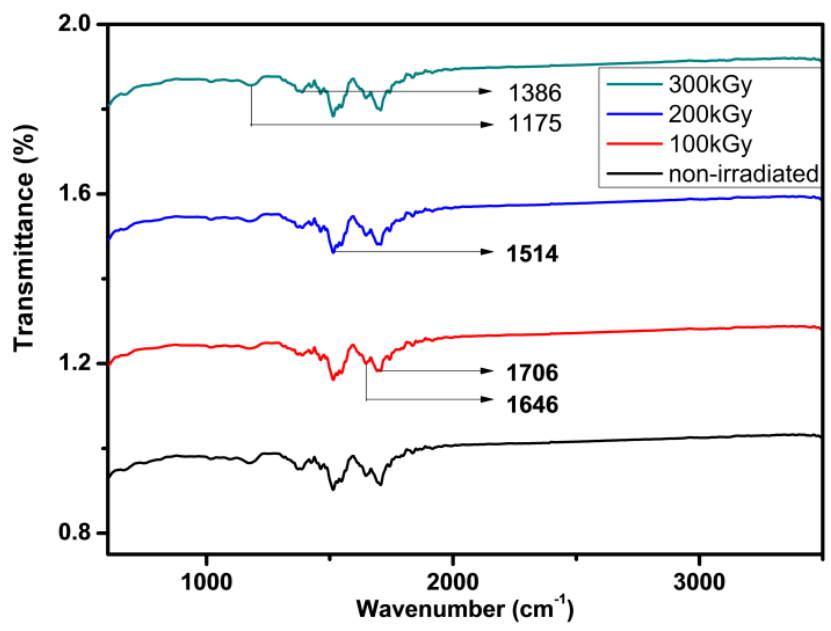

Figure 2: FT-IR spectra of pristine and polymer (5) irradiated with dose of $100 k G y, 200 k G y$ and $300 k G y$

\subsection{XRD Analysis}

The powder XRD of polymer sample $\mathbf{5}$ was recorded between $2 \theta$ range $10^{\circ}-90^{\circ}$ before and after gamma ray irradiation. The pristine showed a halo between $2 \theta$ values of $10^{\circ}-35^{\circ}$ centred at $18.92^{\circ}$. The profile of the halos reveals that the 
polymer samples are partially crystalline with the leading dominant amorphous phase. However, when the sample was irradiated with gamma ray doses of $10 \mathrm{~Gy}$ 's, there were slight shift in the peak position from $18.92^{\circ}$ to $18.31^{\circ}$ for $10 \mathrm{kGy}$ 's and slightly sharpens as seen in Fig. 3. This distinct anomaly phenomenon was observed for only irradiation dose of $10 \mathrm{kGy}$ 's. This may be due to the cross linking of the polymer chains under gamma irradiation leading to the change in short range crystal phases of polymer. This cross linking leads to the re-orientation of polymer chains to the crystalline region. However at higher irradiations (50kGy's and above) the centre of the peaks was shifted to $18.78^{\circ}, 19.00^{\circ}$, $23^{\circ}$ and $23.7^{\circ}$ for polymer sample irradiated with 50,100, 200 and 300kGys respectively and seen as slightly broader indicating the amorphous nature as seen and confirmed by Fig. 3. This is because, at higher gamma doses the polymer chains would undergo chain scission which predominates over the cross coupling of polymer chains. The XRD pattern for non-irradiated and irradiated polymer sample $\mathbf{5}$ is shown in Fig. 3 .

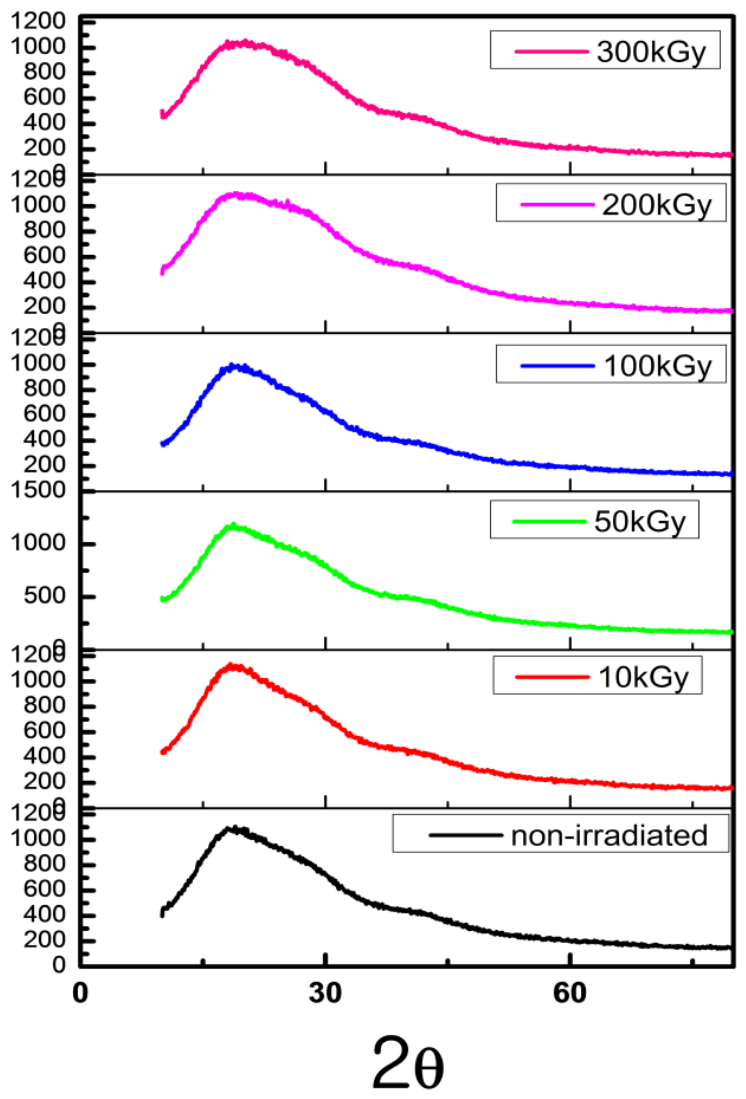

Figure 3: The XRD pattern of pristine and irradiated polymer 5.

\subsection{DSC- TGA Analysis}

The DSC curves for non-irradiated and irradiated polymer samples $\mathbf{5}$ is as shown in Fig. 4 .

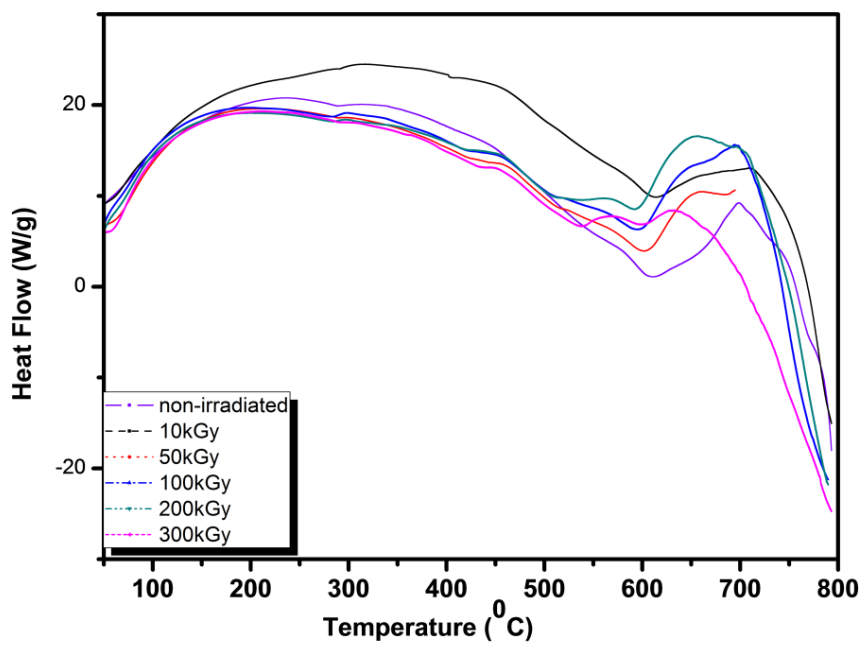

Figure 4: DSC thermograms for pristine and polymer (50 irradiated with different doses gamma rays.

The DSC curves of the pristine and gamma irradiated polymer samples for $\mathbf{5}$ showed no prominent endothermic peaks corresponding to the glass transition temperature $\left(\mathrm{T}_{\mathrm{g}}\right)$. The pristine sample $\mathbf{5}$ showed commencement of oxidation of polymer chains at a temperature of $2360^{\circ} \mathrm{C}$ which further undergo degradation and starts melting above $600^{\circ} \mathrm{C}$. However, the gamma irradiated samples showed a notable increase in resistance to oxidation temperature from $236^{\circ} \mathrm{C}$ to $316.5^{\circ} \mathrm{C}$ at an irradiation dose of $10 \mathrm{kGy}$. This may be due to the cross linking of the polymer chains under gamma irradiation which causes increase in crystalline phase of the polymer by forming new bonds between the chains as evidenced in XRD. But the trend was not similar at higher irradiation doses of 50,100, 200 and 300kGy's where the degradation temperature slightly decreased with increase in irradiation dose. This is because at higher gamma doses the polymer chains would undergo scission that reduces the number of entanglements per molecule which predominates over the cross linking. Chain scission can also act to reduce intermolecular stress in the amorphous region, thus increasing chain mobility. The increase in mobility allows some molecules to re ordered. The exothermic peak positions of the pristine and gamma irradiated samples are given 
Effect of Gamma- Irradiation on Structure, Morphology and Thermal Properties of Novel Polyamide Based Thermoset..........

in Table-2. The percentage weight loss of the pristine and gamma irradiated samples was calculated with respect to their degradation temperature (stage-I) and up to $600^{\circ} \mathrm{C}$ (stage-II) and the results are tabulated in Table-2. The initial weight loss below $100{ }^{\circ} \mathrm{C}$ is due to the loss of moisture content. The onset of major degradation of polymer $\mathbf{5}$ was observed at $236^{\circ} \mathrm{C}$. The weight loss corresponding to this degradation was found to be $5.68 \%$.

The TGA curves for non-irradiated and irradiated polymer samples $\mathbf{5}$ are shown in Fig. 5.

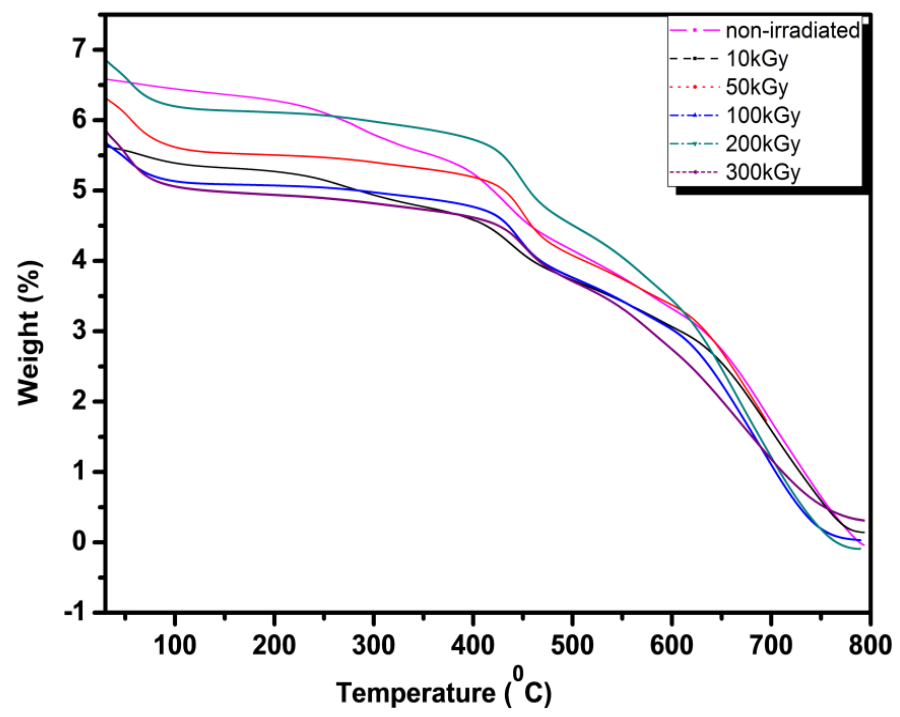

Figure 5: TGA curves for pristine and polymer (5) irradiated with different doses of gamma rays.

Table 2: Percentage weight loss as a function of temperature for pristine and polymer 5 irradiated with different doses of gamma rays.

\begin{tabular}{|c|c|c|c|}
\hline \multirow{2}{*}{$\begin{array}{c}\text { Sample } \\
\text { code- 5 }\end{array}$} & \begin{tabular}{c} 
Thermal \\
Degradation \\
Temperature \\
\cline { 3 - 4 }
\end{tabular} & \multicolumn{2}{|c|}{$\begin{array}{c}\text { Weight Loss (\%) } \\
\left.\text { (Temp. }{ }^{\mathbf{0}} \mathbf{C}\right)\end{array}$} \\
\cline { 3 - 4 } & $\begin{array}{c}\text { Stage- I } \\
\text { at Degradation } \\
\text { temperature) }\end{array}$ & $\begin{array}{c}\text { Stage-II } \\
\text { (at } \\
\mathbf{6 0 0} \mathbf{C})\end{array}$ \\
\hline $\begin{array}{c}\text { Non- } \\
\text { irradiated }\end{array}$ & 236.0 & 5.68 & 46.12 \\
\hline 10kGy & 316.5 & 13.50 & 37.74 \\
\hline $50 \mathrm{kGY}$ & 308.0 & 22.55 & 39.34 \\
\hline $100 \mathrm{kGY}$ & 300.3 & 12.85 & 39.69 \\
\hline $200 \mathrm{kGY}$ & 295.8 & 12.80 & 43.36 \\
\hline $300 \mathrm{kGy}$ & 289.2 & 18.34 & 43.82 \\
\hline
\end{tabular}

a) and b) $1 \mu \mathrm{m} \mathrm{c)} 2 \mu \mathrm{m}$ and d) $10 \mu \mathrm{m}$

The surface of polymer sample $\mathbf{5}$ was seen as massive irregular structures indicating the amorphous nature. It showed spongy type appearance distributed unevenly over the entire surface.The morphological changes observed on surface of polymer samples on gamma irradiation are shown in Fig. 7.
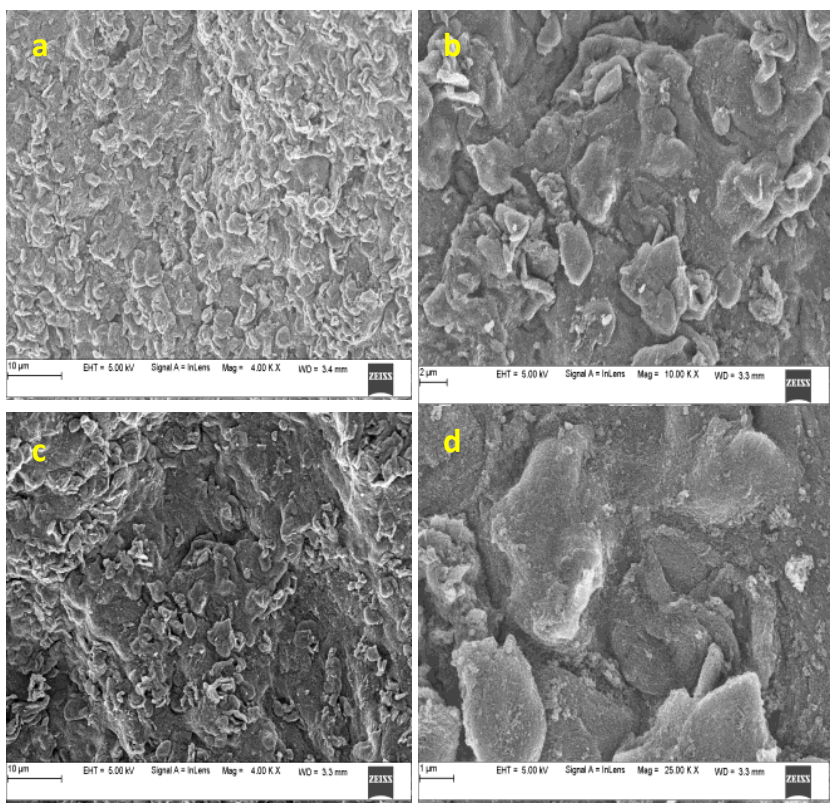

Figure 7: SEM micrographs of irradiated polymer

5 with a dose

a) $100 k G y$ b) $200 k G y$ c) $300 k G y$ and d) $300 k G y$. 
The surface of the sample irradiated with 100kGy was roughened and appeared darker a bit than the pristine and there is no much change in irregularities as seen in image a of Fig. 7. For sample irradiated with $200 \mathrm{kGy}$, the surface was seen to be darker than the sample irradiated with 100kgy. At higher dose of 300kGy, the irregularities on surface decreased a bit but there was no plain appearance that causes due to the surface charring effect on gamma irradiation.

\subsection{UV- Visible Spectroscopy}

The UV-Visible diffuse reflectance spectra of non-irradiated and irradiated polymer sample $\mathbf{5}$ was plotted as a corresponding Kubelka Munks function, $\mathrm{F}(\mathrm{R} \alpha)$ values versus wavelength of $\mathrm{UV}$ Visible radiation. The diffuse reflectance spectrum of pristine and irradiated polymer samples $\mathbf{5}$ is as shown in Fig. 8.

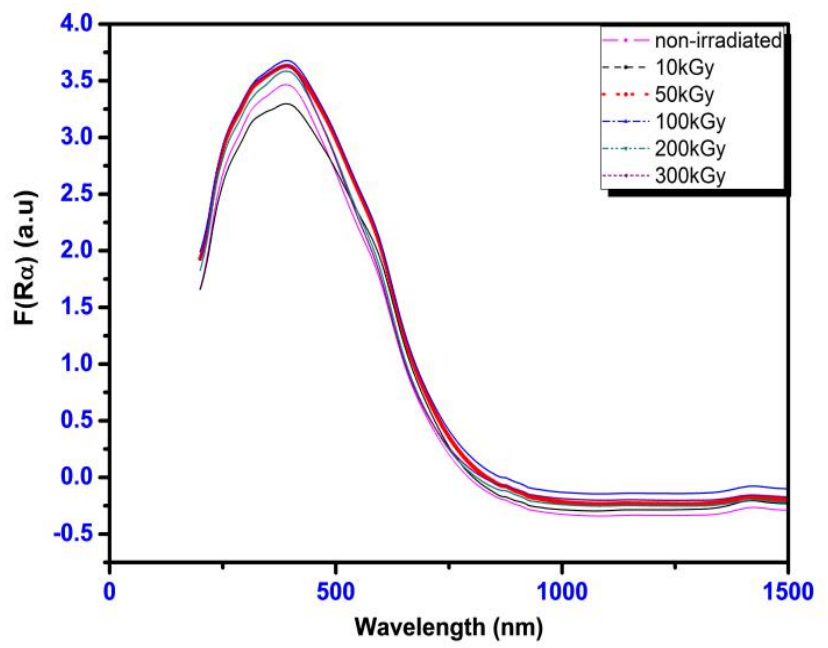

Figure 8: UV-Visible spectra of pristine and polymer (5) irradiated with different doses of gamma rays.

The $\lambda_{\max }$ values corresponding to different irradiation doses are tabulated in Table-3.

Table 3: גmaxvalues for pristine and polymer 5 irradiated with different doses of gamma rays.

\begin{tabular}{|c|c|}
\hline \multirow{2}{*}{ Gamma Dose (kGY) } & $\boldsymbol{\lambda}_{\max }(\mathbf{n m})$ \\
\cline { 2 - 2 } & $\mathbf{5}$ \\
\hline Pristine & 389.90 \\
\hline 10 & 390.00 \\
\hline 50 & 391.15 \\
\hline 100 & 392.34 \\
\hline 200 & 390.60 \\
\hline 300 & 390.20 \\
\hline
\end{tabular}

The diffuse reflectance spectrum of $\mathbf{5}$ showed $\lambda_{\max }$ at 389.90 due to the $\pi-\pi^{*}$ electronic transitions. The gamma irradiated samples of $\mathbf{5}$ showed $\lambda_{\max }$ nearly at the same wavelengths as that of pristine except sample irradiated with 50 and $100 \mathrm{kGY}$ indicating that there is no significant affect of gamma irradiation on the energy levels of the synthesized polymers there by indicating good structural stability towards gamma irradiation dose as evidenced in FT-IR. For this particular dose of 50 and $100 \mathrm{kGy}$ the $\lambda_{\max }$ shifted from $389.90 \mathrm{~nm}$ to $391 \mathrm{~nm}$ and $389.90 \mathrm{~nm}$ to 392 $\mathrm{nm}$ respectively. This increase may be due to the formation of some electronic levels inside the forbidden gap at this irradiation dose. This shift may also be attributed to irradiation-induced defects in the polymeric material. In addition to this, here in this case after irradiation with gamma rays, broadening of absorption edge is observed. This broadening may be due to the formation of some defects due to gamma irradiation, i.e. the formation of conjugated bonds.

\section{Conclusions}

We reported the synthesis of novel macromolecule by a 1,3-dipolar double cycloaddition process and successfully synthesized light weight and excellent material with high chemical and thermal robustness. It exhibits a facile synthetic access to a polyamidebased family of fully aromatic thermosets. The synthesized polymer was tested for its structural and thermal stability before and after gamma irradiation. The thermoset exhibited an affirmative structural and thermal stability even after high gamma irradiation dose of 300kGy as evidenced by FT-IR and DSC-TGA studies. The availability of alternative possible replacement of monomers demonstrates the embryonic potential of this tuneable material platform as a highperformance matrix for the future developing technologies. Finally, this polymer could fit were applications involving exposure to ionizing radiation takes the first priority.

\section{Declarations}

\subsection{Acknowledgements}

The authors are thankful to the Coordinator, DST- PURSE, USIC and Department of Physics, 
Effect of Gamma- Irradiation on Structure, Morphology and Thermal Properties of Novel Polyamide Based Thermoset..........

Mangalore University, for providing facilities for the characterization of polymers and technical support to carry out the work. Authors also acknowledge DAE-BRNS, Mumbai, for the financial support in the form of major research project.

\subsection{Study Limitations}

There was non- availability of GPC instrument for the determination of molecular weight of the synthesized polymer. Most of the GPC instruments are based on Tetrahydrofuran. Our polymer sample was only partial soluble in THF.

\subsection{Funding Source}

Authors are thankful to DAE-BRNS for the financial support.

\subsection{Competing Interests}

Authors declare that there is no conflict of interest exists.

\section{How to Cite this Article:}

B. Kalluraya, K. B R, and H. M. Somashekarappa, "Effect of Gamma- Irradiation on Structure, Morphology and Thermal Properties of Novel Polyamide Based Thermoset Obtained by Double Cycloaddition", J. Mod. Mater., vol. 7, no. 1, pp. 17-25, Jul. 2020. doi:10.21467/jmm.7.1.1725

\section{References}

1. W. D. Ollis and C. A Ramsden, "Meso-ionic compounds," Adv. In Heterocycl. Chem, vol. 19, pp. 1-122,1976. doi.org/10.1016/S0065-2725(08)60230-5

2. V. G Yashunkii, V. F. Vesils and Yu. N Sheinker, Zn. Obshch Kim, 29, 2712 (1959); Chem Abstr, 54, 10999.

3. C. J. Thoman, D. J. Voaden and I. M. Hunsberg, "Direct formylation of sydnones," J. Org. Chem,vol. 29, no. 7, pp. 2044-2045, Jul., 1964. doi.org/10.1021/jo01030a525

4. H. J. Tien and M. Onta, "Acylations of Sydnones," Bull. Chem. Soc, Japan, vol. 45, no. 9, pp. 2944-2945, 1972. doi.org/10.1246/bcsj.45.2944

5. Seetharam Shettigar, Umesh G, Chandrasekharan K, Balakrishna Kalluraya, "Third order nonlinear optical properties and two photon absorptions in newly synthesized phenyl sydnone doped polymer," Synthetic Metals, vol.157, no. 1-3, pp. 142-146, Feb., 2007. doi.org/10.1016/i.synthmet.2007.01.003

6. Raghuvanshi, S.K. Ahmad, B. Siddhartha, Srivastava, A.K. Krishna, J.B.M. Wahab, "Effect of gamma irradiation on the optical properties of UHMWPE (ultrahighmolecular-weight-polyethylene) polymer," Nucl. Instrum. Methods Phys. Res. Sect. B: Beam Interact. Mater. At. Vol. 271, pp. 44-47, Jan.,2012. doi.org/10.1016/j.nimb.2011.11.001

7. M. A. Meador, "Recent advances in the development of processable high-temperature polymers," Аnnu. Rev. Mater. Sci. Vol. 28, pp. 599-630, 1998. doi.org/10.1146/annurev.matsci.28.1.599
8. M .Mujahid, Srivastava, D.S. Gupta, S. Avasthi, "Estimation of optical band gap and carbon cluster sizes formed in heavy ion irradiated polycarbonate," Radiat. Phys. Chem, vol. 74, no. 2, pp. 118-122, oct., 2005. doi.org/10.1016/j.radphyschem.2004.12.008

9. A.F.Saad, S.T Awa, R. Yokota, M. Fujii, " Radiation-induced modifications on spectroscopic and thermal properties of CR-39 and SR-90 nuclear track detectors, " Radiat. Meas. Vol. 40, no.2-6, pp. 780-784, Nov.,2005. doi.org/10.1016/j.radmeas.2005.03.018

10. S.Singh, S.Prasher, "The etching and structural studies of gamma irradiated induced effects in CR-39 plastic track recorder," Nucl. Instrum. Methods Phys. Res, vol. 222, no. 3-4, pp.518- 524, Aug.,2004. doi.org/10.1016/i.nimb.2004.03.004

11. L.Calcagno, G. Compgnini, G. Foti, "Structural modification of polymer films by ion irradiation," Nucl. Instr. Methods Phys, Res, vol. 65, no. 1-4, pp. 413-422, Mar., 1992. doi.org/10.1016/0168-583X(92)95077-5

12. R.Mishra, S.P. Tripathy, K.K. Dwivedi, D.T. Khathing, S. Ghosh, M. Muller, D. Fink, "Electron induced modification in poly(ethylene terephthalate)," Radiat. Eff. Defects Solid, vol. 153, pp. 257-269, 2001. doi.org/10.1080/10420150108211843

13. V.Brunella, M.C. Paganini, "Electron beam radiation effects on UHMWPE: an EPR study,"Magn. Reson. Chem, vol. 49, pp. 562-569, Aug., 2011. doi.org/10.1002/mrc.2781

14. M.S.Mehmood, T. Yasin, M.S. Jahan, B.M. Walters, M. Ahmad, M. Ikram, "EPR study of $\gamma$-irradiated UHMWPE doped with vitamin E: assessment of thermal effects on the organic radicals during vitamin E diffusion," Appl. Magn. Reson, vol. 44, 531-542, 2013. doi.org/10.1007/s00723-012-0421-y

15. V.C. Chappa, M.F. del Grosso, G. García-Bermúdez, R.O. Mazzei, "Infrared spectroscopy analysis of physicochemical modifications induced by heavy ions in ultrahigh molecular weight polyethylene," Nuclear Instruments and Methods in Physics Research B. Vol. 243, no. 1, pp. 58-62, Jan.,2006. doi.org 10.1016/j.nimb.2005.08.121

16. V. Kulshrestha, G.Agarwal, K. Awasthi, D. Vyas, Y. K. Vijay, "Microscopic study of electron and ion irradiated polymeric films," Microscopy: Science, Technology, Applications and Education, 1696, 2010.

17. N L Singh, S. Shah, A. Qureshi, A Tripathi, F Singh, D.K. Avasthi , P M Raole, "Effect of ion beam irradiation on metal particle doped polymer composites," Bull. Mater. Sci, vol. 34, pp. 81-88, May.,2011.10.1007/s12034-0110040-5

18. S. G. Prasad, A. De, U. De, "Structural and Optical Investigations of Radiation Damage in Transparent PET Polymer Films, "International Journal of Spectroscopy, ” Apr., 2011. doi:10.1155/2011/810936

19. S. Siddhartha, Aarya, K. Dev, S. K. Raghuvanshi, J.B.M. Krishna, M.A. Wahab, "Effect of gamma irradiation on structure and optical properties of Polyethyeneterephthalate (PET) polymer," Radiat. Phys. and Chem, vol. 81, no. 4, pp. 458-462, Apr., 2012. doi.org/10.1016/i.radphyschem.2011.12.023

20. S.A. Nouh, Radiyah, A. Baharethc, "Effect of electron beam irradiation on the structural, thermal and optical properties of poly(vinyl alcohol) thin film,"Radiat. Eff. Def. Solids, vol. 168, no. 4, pp. 274-285, 2013. doi.org/10.1080/10420150.2012.741131

21. C. A. C. Bosco, G. S. Maciel, N. Rakov, C. B. Araújo, L. H. Acioli, A. M. Simas, P. F. Athayde-Filho and J. Miller, "Probing the nuclear susceptibility of mesoionic compounds using two-beam coupling with chirpcontrolled pulses," Chem. Phys. Lett, vol. 449, pp. 101106, 2007. doi: 10.1016/j.cplett.2007.10.037.

22. R. S. T. R. Nascimento, C. R. S. Morais, H. L. Lira, S. A. Morais, P. F. Athayde-Filho, L. F. L. Lucena, A. G. 
Souza and G. B. Campos, "Synthesis and characterization of nanocomplexes of $\mathrm{Eu}(\mathrm{III})$ and $\mathrm{Er}(\mathrm{III})$ coordinate with 2(4-clorophenyl)-3-phenyl-1,3,4thiadiazoleo-5-tiolate mesoionic," J. Alloys Comp. Vol. 495. pp. 603-605, $2010 . \quad$ doi: 10.1016/j.jallcom.2009.12.003.

23. S. A.Morais, C. R. S. Morais, P. F. Athayde-Filho, B. F. Lira and R. S. T. R. Nascimento, "A kinetic study of the thermal decomposition of mesoionic compounds within scope of its application in nonlinear optical devices," $J$. Therm. Anal. Calorim, vol. 97, pp. 437-441, 2009. doi: 10.1007/s10973-009-0082-8.

24. B. F. Lira, S. A. Morais, G. B. Rocha, J. Miller, G. L. C. Moura, A. M. Simas, C. Peppe and P. F. Athayde-Filho, "1,3-Thiazolium-5-thiolates mesoionic compounds: Semiempirical evaluation of their first static hyperpolarizabilities and synthesis of new examples," $J$. Braz. Chem. Soc, vol. 21, pp. 934-940, 2010. doi: 101590/S0103-505320100000500024.

25. A. S.-Ribeiro, A. Echevarria, E. F. Silva, C. R. C. Franco, S. S. Veiga and M. B. M. Oliveira, "Cytotoxic effect of a new 1,3,4-thiadiazolium mesoionic compound (MI-D) on cell lines of human melanoma," Br. J. Cancer, vol. 91, pp. 297-304, 2004. doi:10.1038/sj.bjc.6601946.

26. R. F. Rodrigues, E. F. Silva, A. Echevarria, R. Fajardo-Bonin, V. F. Amaral, L. L. Leon and M. M. Canto-Cavalheiro, "A comparative study of mesoionic compounds in Leishmania sp. and toxicity evaluation," Eur. J. Med. Chem, vol. 42, pp. 1039-1043, 2007. doi:10.1016/j.ejmech.2006.12.026.

27. R. F. Rodrigues, D. Castro-Pinto, A. Echevarria, C.M. Reis, C. N. Del Cistia, C. M. R. Sant'Anna, F. Teixeira, H. Castro, M. Canto-Cavalheiro, L. L. Leon and A. Tomás, "Investigation of tripanothione redutase inhibitory activity by 1,3,4-thiadiazolium-2-aminide derivatives and molecular docking studies," Bioorg. Med. Chem, vol. 20, pp. 1760-1766, 2012. doi: 10.1016/j.bmc.2012.01.009.

28. K. L. M. Cavalcante, N. A. Correia, K. L. G. Dias, D. F. Silva, J. C. Silva-Filho, I. G. A. Araújo, B. F. Lira, P. F. Athayde-Filho and I. A. Medeiros, "Endotheliumderived nitric oxide contributes to the vaso relaxant response induced by mesoionic 2-(4-chlorophenyl)-3methyl-4-(4-methoxyphenyl)-1,3-thiazolium-5-thyolate (CMMTT) in rats," J. Pharmacol. Sci, vol. 110, pp. 2935; doi:10.1254/jphs.FP0071581.

29. K. Rehse, T. Ciborski and B. Müller, "Platelet aggregation inhibiting and anticoagulant effects of oligoamines. XXVII. Inhibition of leucocyte adherence to endothelium by oligoamine RE $1492 \mathrm{C}$ and the NO-donor RE 2047," Arch. Pharm, vol. 328, pp. 125-126, 1995. doi: 10.1002/ardp.19953280206.

30. L. B. Kier and E. B. Roche, "Medicinal chemistry of the mesoionic compounds," J. Pharm. Sci. vol. 56, pp. 149168, 1967. doi: 10.1002/jps.2600560202.

31. C. S. Oliveira, V. S. Falcão-Silva, J. P. Siqueira-Júnior, D. P. Harding, B. F. Lira, J. G. F. Lorenzo, J. M. Barbosa-Filho and P. F. Athayde-Filho, "Drug resistance modulation in Staphylococcus aureus, a new biological activity for mesoionic hydrochloride compounds," Molecules, vol. 16, pp. 2023-2031, 2011. doi: 10.3390/molecules16032023

32. Liqiang Wan, Yonghong Luo, Lian Xue, Jianjun Tian, Yanhong Hu, Huimin Qi, Xuening Shen, Farong Huang, Lei Du, Xiangbao Chen, "Preparation and properties of a novel polytriazole resin," J. Appl. Polym. Sci, ,vol.104, pp. 2007. doi.org/10.1002/app.24849

33. Mihrace Ergin, Baris Kiskan, Burcin Gacal, Yusuf Yagci, "Thermally Curable Polystyrene via Click Chemistry," Macromolecules, vol. 40, pp. 4724-4727, 2007. doi.org/10.1021/ma070549j
34. Balakrishna Kalluraya, B. R. Kaushik, H. M. Somashekarappa, "Effect of gamma- irradiation on fully aromatic high performance novel thermosets and study of their physico-chemical properties,"Radiation physics and Chemistry,vol. 168, Mar.,2020. doi. Org/10.1016/radphyschem.2019.108533

35. Balakrishna Kalluraya, B. R. Kaushik, T. Vishwanath, "H. M. Someshekarappa, Effect of $\Upsilon$ - irradiation and study of $\Upsilon$ induced physico-chemical changes in high performance thermoset obtained by double cycloaddition of munchnone and bis-maleimide," Radiation Effect and defects in solids, Apr., 2020. doi.org/10.1080/10420150.2020.1759066

36.M. K. McBride, T. Gong, D. P. Nair, and C. N. Bowman, "Photo-mediated copper(I)-catalyzed azide-alkyne cycloaddition (CuAAC) "click" reactions for forming polymer networks as shape memory materials," Polymer, vol. 55, no. 23, pp. 5880-5884, Nov., 2014. doi.org/10.1016/j.polymer.2014.08.001

37. K. Sykam and S. Donempudi, "Novel multifunctional hybrid diallyl ether monomer via azide alkyne click reaction as crosslinking agent in protective coatings,"Polymer, vol. 62, pp. 60-69, Apr., 2015. doi.org/10.1016/j.polymer.2015.02.017

38. C. Ornelas, J. Broichhagen, and M. Weck, "Strain-Promoted Alkyne Azide Cycloaddition for the Functionalization of Poly(amide)-Based Dendrons and Dendrimers," J. Am. Chem. Soc., vol. 132, no.11, pp.3923-3931, Feb., 2010. doi.org/10.1021/ja910581d

39. M. Fan, Y. Ma, J. Mao, Z. Zhang, and H. Tan, "Cytocompatible in situ forming chitosan/hyaluronan hydrogels via a metal-free click chemistry for soft tissue engineering,"Acta Biomater., vol. 20, pp. 60-68, Jul., 2015. doi.org/10.1016/j.actbio.2015.03.033

40.J. C. Jewett and C. R. Bertozzi, "Cu-free click cycloaddition reactions in chemical biology,"Chem. Soc. Rev., vol. 39, no. 4, pp. 1272-1279, Jan., 2010. doi.org/10.1039/B901970G

41.R. J. Su, H. W. Yang, Y. L. Leu, M. Y. Hua, and R. S. Lee, "Synthesis and characterization of amphiphilic functional polyesters by ring-opening polymerization and click reaction," React. Funct. Polym., vol. 72, no. 1, pp. 36-44, Jan., 2012. doi.org/10.1016/j.reactfunctpolym.2011.08.008

42. S. Yigit, R. Sanyal, and A. Sanyal, "Fabrication and Functionalization of Hydrogels through "Click" Chemistry," Chem. Asian J., vol. 6, pp. 2648-2659, 2011. doi.org/10.1002/asia.201100440

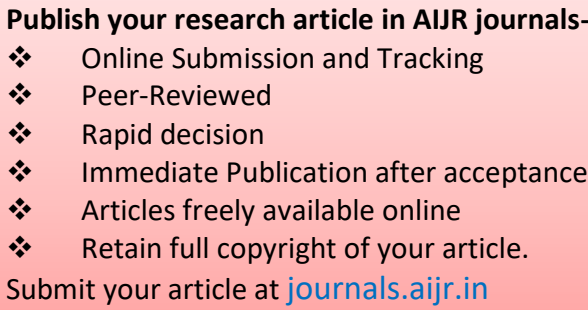

